\title{
Red Cell Distribution Width as a Predictor of Prostate Cancer Progression
}

\author{
Sebahattin Albayrak*, Kursad Zengin, Serhat Tanik, Hasan Bakirtas, \\ Abdurrahim Imamoglu, Mesut Gurdal
}

\begin{abstract}
Background: The aims of this study were to investigate the utility of red blood cell distribution width (RDW) as a simple and readily available marker in prostate cancer, as well as to evaluate RDW as a predictor of progression in prostate cancer patients. Materials and Methods: We evaluated 62 newly diagnosed prostate cancer patients who underwent transrectal ultrasound (TRUS)-guided biopsy and 62 healthy controls of mean age 64 (range, 45-75) years at the Urology Clinic of Bozok University Hospital. Data collection was performed using our laboratory information system database to retrieve findings regarding RDW, hemoglobin, prostatespecific antigen (PSA), and age. The RDW values were compared between the healthy control group and prostate cancer patients. A high risk of progression as defined as a Gleason score (GS) $>\mathbf{6}$, total number of cores positive for cancer $>33 \%$, each core containing $>50 \%$ cancer cells, and a prostate-specific antigen (PSA) level $>10 \mathrm{ng}$ / mL. Patients were classified according to risk of progression, as well as divided into subgroups according to the RDW quartile. Results: The mean RDW value of prostate cancer patients was 14.6, compared with 13.7 in the healthy control group $(\mathrm{p}=\mathbf{0 . 0 0 1})$. A higher $\mathrm{RDW}$ was associated with an increased risk of progression, whereas a lower RDW value was correlated with a low risk of progression. Conclusions: RDW is an easily derived measure that might, in combination with other markers, help predict prostate cancer risk and progression. We suggest that RDW may be used in combination with other parameters in the assessment of prostate cancer.
\end{abstract}

Keywords: Prostate cancer - progression - red blood cell distribution width

Asian Pac J Cancer Prev, 15 (18), 7781-7784

\section{Introduction}

Prostate cancer is the most common urological cancer and the third most common cancer worldwide (2010). Prostate cancer remains one of the major public health problems worldwide (Leitzmann and Rohrmann, 2012; Siegel et al., 2012). Prostate cancer is a form of malignancy that is most likely to develop in older males, but because of the propensity to metastasize to parts of the body, especially the bones, can have a harmful impact on quality of life (Wang et al., 2013).

Inflammation increases the incidence of prostate cancer, similarly to other cancer types (Cheng et al., 2010; Nonomura et al., 2010; Fujita et al., 2012; Sfanos and De Marzo, 2012). Inflammatory cells release a number of oxidative molecules, which may lead to genomic and cellular damage. These factors increase the risk for prostate cancer and can cause infectious gene mutations. Similarly, molecular pathological studies have suggested that inflammation increases the risk of prostate cancer (Nelson and Harris, 2000; Shah et al., 2001; Cheng et al., 2010; Sfanos and De Marzo, 2012). Furthermore, Dennis and Dawson reported an increased risk for prostate cancer in the presence of inflammation in patients with sexually transmitted diseases (Dennis and Dawson, 2002). In addition, Nelson and Harris reported that some antioxidants and anti-inflammatory agents reduced the risk of prostate cancer (Nelson and Harris, 2000).

Red blood cell distribution width (RDW) is an automated measure of the heterogeneity of red blood cell dimensions (e.g., anisocytosis) and is performed routinely as part of a complete blood cell count. Some previous studies and a meta-analysis demonstrated that RDW is a potent predictor of all-cause mortality, including cancer-related deaths (Patel et al., 2009; Perlstein et al., 2009; Patel et al., 2010). There is also a strong, graded association between RDW and inflammatory biomarkers (fibrinogen, serum C-reactive protein [CRP], and erythrocyte sedimentation rate [ESR]), which is independent of numerous confounding factors (Cakal et al., 2009; Lippi et al., 2009). RDW, which makes up part of the complete blood count (CBC), has been hypothesized to correlate with the duration of several diseases including occult colon cancer, liver disease, heart failure, migraine, and celiac disease (Maruyama et al., 2001; Mitchell and Robinson, 2002; Spell et al., 2004; Ozkalemkas et al., 2005; Felker et al., 2007; Celikbilek et al., 2013). Therefore, RDW is an indicator of the overall 
inflammatory status of the body, and it might be altered in prostate cancer patients. The aims of this study were to investigate the utility of RDW as a simple and readily available marker in prostate cancer and to evaluate RDW as a predictor of progression in prostate cancer patients.

\section{Materials and Methods}

We evaluated 62 newly diagnosed prostate cancer patients who underwent transrectal ultrasound (TRUS)guided biopsy and 62 healthy controls of mean age 64 (range, 45-75) years at the Urology Clinic of Bozok University Hospital from 1 January 2012 to 31 October 2013. We selected 124 consecutive patients was performed using our laboratory information system database to retrieve data regarding RDW, hemoglobin, prostatespecific antigen (PSA), and age. TRUS-guided biopsies were assessed by examining the patient files. RDW values were compared between the healthy control group and prostate cancer patients. A high risk of progression was defined as a Gleason score (GS) $>6$, total number of cores positive for cancer $>33 \%$, each core containing $>50 \%$ of the volume of the disease, and a prostate-specific antigen (PSA) level >10 ng/mL (Sooriakumaran et al., 2012; Odom et al., 2013). Patients were classified according to risk of progression as well as divided into subgroups according to the RDW quartile.

\section{Statistical analysis}

Shapiro-Wilk's and Levene's tests were used to test the normality and variance homogeneity of the data. RDW was categorized into quartiles. Independentsamples t-tests, paired t-tests, and one-way analysis of variance were used to compare continuous variables, and chi-squared tests were used for categorical variables. Values are expressed as frequencies and percentages, means \pm standard deviations, or medians and 25th-75th percentiles. Receiver operating characteristic (ROC) curves were constructed for PSA, RDW, CRP, and N/L variables, and the areas under the ROC curve values along with $95 \%$ confidence intervals (95\% CIs) were

Table 1. Baseline Characteristics of Patients $(n=124)$

\begin{tabular}{lccc}
\hline Characteristic & $\begin{array}{c}\text { Prostate } \\
\text { cancer } \\
\text { mean } \pm \text { SD }\end{array}$ & $\begin{array}{c}\text { Healthy } \\
\text { control } \\
\text { mean } \pm \text { SD }\end{array}$ & $\begin{array}{c}\text { All } \\
\text { patients } \\
\text { mean } \pm \text { SD }\end{array}$ \\
\hline Age (years): & $65.0 \pm 14$ & $63.0 \pm 13$ & $64.0 \pm 14$ \\
Hemoglobin $(\mathrm{g} / \mathrm{dL}):$ & $14.3 \pm 1$ & $14.5 \pm 1$ & $14.4 \pm 1$ \\
RDW: $(\%)$ & $14.55 \pm 1$ & $13.70 \pm 0.9$ & $14.12 \pm 1$ \\
C-reactive protein $(\mathrm{mg} / \mathrm{L})$ & $0.93 \pm 0.1$ & $0.88 \pm 0.1$ & $0.9 \pm 0.1$ \\
Erythrocyte sedimentation rate $(\mathrm{mm} / \mathrm{h})$ & $8.5 \pm 1.2$ & $8.2 \pm 1.1$ & $8.3 \pm 1.2$ \\
\hline
\end{tabular}

calculated and compared. The optimal cut-off values were determined, and the sensitivity, specificity, positive predictive rate, negative predictive rate, and accuracy rate of the diagnostic measures were calculated using 95\% CIs. Statistical analyses were performed using SPSS version 15.0 (SPSS Inc., Chicago, IL, USA), and the level of statistical significance was set at $\mathrm{p}<0.05$.

\section{Results}

There were no significant differences in age or hemoglobin levels between the prostate cancer and healthy groups $(p=0.223$ and $p=0.296$, respectively; Table 1$)$. The distributions of prostate cancer patients according to RDW quartile were $13.3 \%, 25 \%, 35.9 \%$, and $44.8 \%$, respectively. The mean RDW value of the prostate cancer patients was 14.55 , compared with 13.70 in the healthy control group ( $\mathrm{p}=0.001$; Table 1$)$. The RDW values were higher in patients at a high risk of progression than a low risk of progression, but only the number of cores containing $>50 \%$ volume was statistically significant between groups (Table 2). The distribution of patients at a high risk of progression according to the RDW quartile is shown in Table 3. Patients in higher RDW quartiles have a high risk of Progression according to all progression criteria. The RDW cut-off of 13.89 determined via ROC curve analysis had a sensitivity of $81 \%$ and a specificity of $62 \%$ (Figure 1). Among the individuals with an RDW

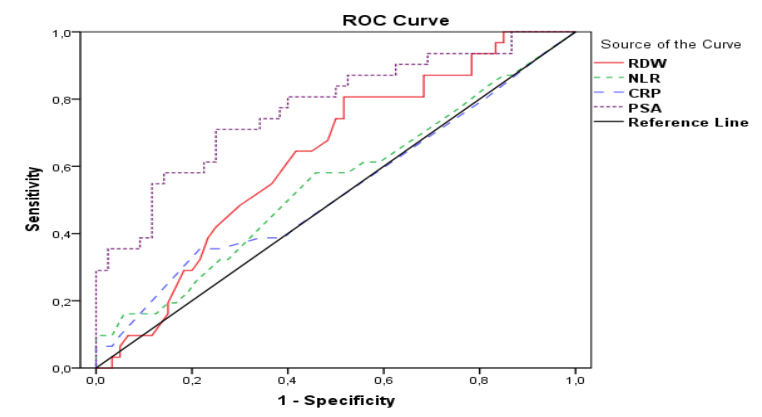

Figure 1. Example of an ROC Curve

Table 2. Progression Criteria According to RDW values $(\mathbf{n}=62)$

\begin{tabular}{lccc}
\hline Criteria of progression & $\mathrm{N}$ & RDW mean \pm S.D & p value \\
\hline Gleason score $>6$ & 30 & $14.7 \pm 0.6$ & \\
Gleason score $\leq 6$ & 32 & $14.3 \pm 1$ & 0.067 \\
Total positive cores $>33 \%$ & 34 & $14.6 \pm 0.7$ & \\
Total positive cores $\leq 33 \%$ & 28 & $14.3 \pm 0.8$ & 0.172 \\
Core cancer volume $>50 \%$ & 36 & $14.7 \pm 0.8$ & \\
Core cancer volume $\leq 50 \%$ & 26 & $14.1 \pm 0.8$ & 0.007 \\
PSA $>10 \mathrm{ng} / \mathrm{ml}$ & 36 & $14.7 \pm 0.6$ & \\
PSA $\leq 10 \mathrm{ng} / \mathrm{ml}$ & 26 & $14.2 \pm 0.8$ & 0.061 \\
\hline
\end{tabular}

Table 3. Distribution of Patients with High Risk of Progression According to their RDW Quartiles (n=62)

\begin{tabular}{|c|c|c|c|c|c|}
\hline \multirow[t]{2}{*}{ High risk of progression criteria } & \multicolumn{4}{|c|}{ RDW Quartiles } & \multirow[b]{2}{*}{$\begin{array}{l}\mathrm{P} \text { value } \\
\text { for trend }\end{array}$} \\
\hline & $\begin{array}{c}\mathrm{I} \\
\leq 13.1 \% \\
(\mathrm{n}=14)\end{array}$ & $\begin{array}{c}\text { II } \\
13.2 \%-13.6 \% \\
(n=15)\end{array}$ & $\begin{array}{c}\text { III } \\
13.7 \%-14.7 \% \\
(\mathrm{n}=17)\end{array}$ & $\begin{array}{c}\mathrm{IV} \\
\geq 14.8 \% \\
(\mathrm{n}=16)\end{array}$ & \\
\hline Gleason score $>6$ & $0 \%$ & $0 \%$ & $35.7 \%$ & $76.9 \%$ & $<0.001$ \\
\hline Total positive cores $>33 \%$ & $0 \%$ & $35 \%$ & $50.0 \%$ & $84.6 \%$ & 0.001 \\
\hline Core cancer volume $>50 \%$ & $0 \%$ & $50 \%$ & $57.1 \%$ & $92.3 \%$ & 0.001 \\
\hline $\mathrm{PSA}>10 \mathrm{ng} / \mathrm{ml}$ & $0 \%$ & $50 \%$ & $57.1 \%$ & $76.9 \%$ & 0.021 \\
\hline
\end{tabular}


value $>13.89,61.7 \%$ had prostate cancer, compared with $27.9 \%$ of those with an RDW value $<13.89$ (p<0.001).

\section{Discussion}

The current study showed that the RDW values of prostate cancer patients were significantly higher than those of the healthy control group. A higher RDW was associated with an increased risk of progression, whereas a lower RDW value was associated with a low risk of progression. Furthermore, the RDW values of prostate cancer patients at a high risk of progression were higher than those of other prostate cancer patients, but only the number of cores containing $>50 \%$ of the volume of the disease was a statistically significant factor.

Prostatic lesions known as proliferative inflammatory atrophy and prostatic intraepithelial neoplasia are precursors of prostate cancer (Nelson and Harris, 2000; Shah et al., 2001; Cheng et al., 2010; Sfanos and De Marzo, 2012). Despite recent improvements in diagnostic and therapeutic approaches, prostate cancer remains one of the leading health problems worldwide and is associated with high morbidity and mortality rates. Early diagnosis and treatment of the disease is critical to prevent morbidity (Beer et al., 2008; 2010). To date, certain inflammatory biomarkers have been investigated for their potential role in prostate carcinogenesis (Mengus et al., 2011), and a role for inflammation in carcinogenesis is becoming increasingly accepted (Kundu and Surh, 2008; Emerging Risk Factors et al., 2010). In the current study, the mean RDW values of prostate cancer patients were significantly higher than those in the healthy control group $(\mathrm{p}=0.001)$. The observation that RDW, an inflammatory marker, was high in prostate cancer patients suggests a possible relationship between prostate cancer and inflammation.

With the recent introduction of novel diagnostic instruments, prostate cancer can be diagnosed readily (Dennis and Dawson, 2002). The current study revealed that the rate of prostate cancer increased concurrently and significantly with the RDW quartile $(13.3 \%, 25 \%, 35.9 \%$, and $44.8 \%$, respectively; $\mathrm{p}=0.02)$. The observation of higher RDW values in prostate cancer patients compared with the healthy control group and the correlation between the rate of prostate cancer and RDW values suggested that higher RDW values could be used together with other parameters for predicting prostate cancer. Similarly, more prostate cancer patients were identified among individuals with an RDW above the 13.89 cut-off value determined by ROC curve analysis, which suggested that a cut-off of 13.89 can be used in combination with other parameters to predict prostate cancer.

Prognostic markers that can identify aggressive prostate cancer in early stages and help select appropriate therapy to finally reduce the mortality are therefore urgently needed (Ferronika et al., 2012). Sooriakumaran at al. analyses show that PSA, number of positive cores, and lower prostate volume are significant predictors of upgrading or upstaging in patients assumed eligible for active surveillance by conventional criteria (Sooriakumaran et al., 2012). Recently, however, it has been largely reported that leukocytosis as well as neutrophilto-lymphocyte ratio and multiplied neutrophils and lymphocytes may be a diagnostic and prognostic tumor biomarker (Cihan et al., 2013). The results of the current study revealed that, according to RDW quartiles, no patients at a high risk of progression belonged in group I. This suggests that prostate cancer patients with low RDW values $(\leq 13.1)$ are considered to be at low risk of progression. Furthermore, RDW values could provide guidance to help plan patient follow-ups and treatments. In groups II, III, and IV, an increasing risk of progression was identified using all the progression criteria. The fact that progression risk and RDW values increase gradually in parallel suggests that patients with higher RDW values are at increased risk of prostate cancer progression.

It was reported that inflammation plays a role in the progression of solid tumors, although it remains unclear whether the aggressive disease was caused by increased inflammation or whether the inflammation was caused by aggressive disease (Kazma et al., 2012; Klink et al., 2013). The inflammation score predicts both cancer and cardiovascular disease mortality (Godsland et al., 2011). In cancer, ESR has only been studied as a predictor of progression (Henry-Amar et al., 1991; Borre et al., 1997). Bear et al. reported that elevated C-reactive protein (CRP) levels were related to poor prognosis in patients with metastatic prostate cancer (Beer et al., 2008). A study by Odom at al. reported a higher risk of disease progression in a patient who underwent active surveillance for lowrisk prostate cancer, suggesting a potential need for closer follow-up and more stringent enrollment criteria (Odom et al., 2014). Several studies suggested that the neutrophilto-lymphocyte ratio was a prognostic factor for colorectal and non-small cell cancer. Other studies revealed that the neutrophil-to-lymphocyte ratio was related to poor prognosis (Walsh et al., 2005; Cho et al., 2009; Cho and Kim, 2009). The results of the current study suggest that the presence of a systemic inflammatory reaction at diagnosis was an independent predictor of poor long-term cancer outcomes in patients with localized prostate cancer (McArdle et al., 2010). The current study suggests that the use of RDW values and other parameters could be beneficial for predicting prostate cancer outcome. This might be useful to consider for more careful follow-up and treatment planning of prostate cancer patients with high RDW values with respect to progression.

Based on the findings of the current study, we recommend that RDW, a very common, easy, and simple marker, should be considered for treatment planning and follow-up of prostate cancer patients. RDW, in combination with other markers, might help predict prostate cancer risk and progression. The observation that RDW, an indicator of inflammation, was correlated with other parameters predictive of progression and aggressiveness of prostate cancer suggests the potential association of an inflammatory cascade with cancer aggressiveness and progression. We suggest that RDW may be used in combination with other parameters in the diagnosis of prostate cancer. 


\section{References}

Beer TM, Lalani AS, Lee S, et al (2008). C-reactive protein as a prognostic marker for men with androgen-independent prostate cancer: results from the ASCENT trial. Cancer, 112, 2377-83.

Borre M, Nerstrom B, Overgaard J (1997). Erythrocyte sedimentation rate-a predictor of malignant potential in early prostate cancer. Acta Oncol, 36, 689-94.

Cakal B, Akoz AG, Ustundag Y, et al (2009). Red cell distribution width for assessment of activity of inflammatory bowel disease. Digestive Diseases and Sciences, 54, 842-7.

Celikbilek A, Zararsiz G, Atalay T, et al (2013). Red cell distribution width in migraine. Int J Lab Hematol, 35, 620-8.

Cheng I, Witte JS, Jacobsen SJ, et al (2010). Prostatitis, sexually transmitted diseases, and prostate cancer: the California men's health study. PLoS One, 5, 8736.

Cho H, Hur HW, Kim SW, et al (2009). Pre-treatment neutrophil to lymphocyte ratio is elevated in epithelial ovarian cancer and predicts survival after treatment. Cancer Immunol Immunother, 58, 15-23.

Cho H, Kim JH (2009). Multiplication of neutrophil and monocyte counts (MNM) as an easily obtainable tumour marker for cervical cancer. Biomarkers, 14, 161-70.

Cihan YB, Arslan A, Ergul MA (2013). Subtypes of white blood cells in patients with prostate cancer or benign prostatic hyperplasia and healthy individuals. Asian Pac J Cancer Prev, 14, 4779-83.

Dennis LK, Dawson DV (2002). Meta-analysis of measures of sexual activity and prostate cancer. Epidemiology, 13, 72-9.

Emerging Risk Factors C, Kaptoge S, Di Angelantonio E, et al (2010). C-reactive protein concentration and risk of coronary heart disease, stroke, and mortality: an individual participant meta-analysis. Lancet, 375, 132-40.

Felker GM, Allen LA, Pocock SJ, et al (2007). Red cell distribution width as a novel prognostic marker in heart failuredata from the charm program and the duke databank. $J$ Am College Cardiol, 50, 40-7.

Ferronika P, Triningsih FX, Ghozali A, et al (2012). p63 cytoplasmic aberrance is associated with high prostate cancer stem cell expression. Asian Pac J Cancer Prev, 13, 1943-8.

Fujita K, Imamura R, Tanigawa G, et al (2012). Low serum neutrophil count predicts a positive prostate biopsy. Prostate Cancer Prostatic Dis, 15, 386-90.

Godsland IF, North BV, Johnston DG (2011). Simple indices of inflammation as predictors of death from cancer or cardiovascular disease in a prospective cohort after two decades of follow-up. Qjm-an Int J Med, 104, 387-94.

Henry-Amar M, Friedman S, Hayat M, et al (1991). Erythrocyte sedimentation rate predicts early relapse and survival in early-stage Hodgkin disease. The EORTC Lymphoma Cooperative Group. Ann Intern Med, 114, 361-5.

Japanese Urological Association (2010). Committee for Establishment of the Guidelines on Screening for Prostate Cancer1; Updated Japanese urological association guidelines on prostate-specific antigen-based screening for prostate cancer in 2010. Int J Urol, 17, 830-8.

Kazma R, Mefford JA, Cheng I, et al (2012). Association of the Innate Immunity and Inflammation Pathway with Advanced Prostate Cancer Risk. Plos One, 7.

Klink JC, Banez LL, Gerber L, et al (2013). Intratumoral inflammation is associated with more aggressive prostate cancer. World J Urol, 31, 1497-503.

Kundu JK, Surh YJ (2008). Inflammation: gearing the journey to cancer. Mutat Res, 659, 15-30.

Leitzmann MF, Rohrmann S (2012). Risk factors for the onset of prostatic cancer: age, location, and behavioral correlates.
Clin Epidemiol, 4, 1-11.

Lippi G, Targher G, Montagnana M, et al (2009). Relation between red blood cell distribution width and inflammatory biomarkers in a large cohort of unselected outpatients. Arch Pathol Laboratory Med, 133, 628-32.

Maruyama S, Hirayama C, Yamamoto S, et al (2001). Red blood cell status in alcoholic and non-alcoholic liver disease. $J$ Laboratory Clin Med, 138, 332-7.

McArdle PA, Qayyum T, McMillan DC (2010). Systemic inflammatory response and survival in patients with localised prostate cancer: 10-year follow-up. Urol Int, 84, 430-5.

Mengus C, Le Magnen C, Trella E, et al (2011). Elevated levels of circulating IL-7 and IL-15 in patients with early stage prostate cancer. J Transl Med, 9, 162.

Mitchell RMS, Robinson TJ (2002). Monitoring dietary compliance in coeliac disease using red cell distribution width. Int J Clin Practice, 56, 249-50.

Nelson JE, Harris RE (2000). Inverse association of prostate cancer and non-steroidal anti-inflammatory drugs (NSAIDs): Results of a case-control study. Oncology Reports, 7, 169-70.

Nonomura N, Takayama H, Kawashima A, et al (2010). Decreased infiltration of macrophage scavenger receptorpositive cells in initial negative biopsy specimens is correlated with positive repeat biopsies of the prostate. Cancer Sci, 101, 1570-3.

Odom BD, Mir M, Hughes S, et al (2013). Active surveillance for low-risk prostate cancer in African American men: A multi-institutional experience. Urology, 83, 364-8.

Ozkalemkas F, Ali R, Ozkocaman V, et al (2005). The bone marrow aspirate and biopsy in the diagnosis of unsuspected nonhematologic malignancy: A clinical study of 19 cases. Bmc Cancer, 5, 144.

Patel KV, Ferrucci L, Ershler WB, et al (2009). Red blood cell distribution width and the risk of death in middle-aged and older adults. Arch Intern Med, 169, 515-23.

Patel KV, Semba RD, Ferrucci L, et al (2010). Red cell distribution width and mortality in older adults: a metaanalysis. J Gerontol A Biol Sci Med Sci, 65, 258-65.

Perlstein TS, Weuve J, Pfeffer MA, et al (2009). Red blood cell distribution width and mortality risk in a community-based prospective cohort. Arch Intern Med, 169, 588-94.

Sfanos KS, De Marzo AM (2012). Prostate cancer and inflammation: the evidence. Histopathol, 60, 199-215.

Shah R, Mucci NR, Amin A, et al (2001). Postatrophic hyperplasia of the prostate gland: neoplastic precursor or innocent bystander? Am J Pathol, 158, 1767-73.

Siegel R, DeSantis C, Virgo K, et al (2012). Cancer treatment and survivorship statistics, 2012. CA Cancer J Clin, 62, 220-41.

Sooriakumaran P, Srivastava A, Christos P, et al (2012). Predictive models for worsening prognosis in potential candidates for active surveillance of presumed low-risk prostate cancer. Int Urol Nephrol, 44, 459-70.

Spell DW, Jones DV, Harper WF, et al (2004). The value of a complete blood count in predicting cancer of the colon. Cancer Detection Prev, 28, 37-42.

Walsh SR, Cook EJ, Goulder F, et al (2005). Neutrophillymphocyte ratio as a prognostic factor in colorectal cancer. J Surg Oncol, 91, 181-4.

Wang J, Yang J, Zou Y, et al (2013). Orphan nuclear receptor nurr1 as a potential novel marker for progression in human prostate cancer. Asian Pac J Cancer Prev, 14, 2023-8. 